\title{
Caracterização bioquímica de linhagens de soja com alto teor de proteína
}

\author{
Rita Maria Alves de Moraes $^{(1)}$, Inês Chamel José(2), Fernanda Gomes Ramos(2), \\ Everaldo Gonçalves de Barros ${ }^{(2)}$ e Maurilio Alves Moreira(2)
}

\begin{abstract}
(1)Embrapa Trigo, Rod. BR 285, Km 174, Caixa Postal 451, CEP 99001-970 Passo Fundo, RS. E-mail: rita@cnpt.embrapa.br (2)Bioagro, Universidade Federal de Viçosa, Campus Universitário, CEP 36570-000 Viçosa, MG. E-mail: ichamel@ufv.br, fernandagramos@ig.com.br, ebarros@ufv.br, moreira@ufv.br
\end{abstract}

\begin{abstract}
Resumo - O objetivo deste trabalho foi caracterizar bioquimicamente duas isolinhas de soja com alto teor de proteína. O aumento do teor de proteína nas isolinhas foi acompanhado por redução no teor de óleo e de carboidratos totais. Em relação à composição aminoacídica, o aumento do teor de proteína promoveu acréscimo em todos os aminoácidos, exceto glicina, alanina, metionina, cisteína e tirosina, mantendo a relação enxofre/ nitrogênio. A quantificação dos polipeptídios mostrou que o aumento do teor de proteína manteve inalterado o teor das proteínas 7S, promoveu aumento no teor das proteínas 11S e, conseqüentemente, da relação 11S/7S. Pode haver melhoria na qualidade do farelo de soja das isolinhas, uma vez que as proteínas $11 \mathrm{~S}$ têm melhor qualidade nutricional do que as proteínas 7S.
\end{abstract}

Termos para indexação: Glycine max, aminoácidos, metionina, cisteína, 7S, 11S.

\section{Biochemical characterization of high protein soybean lines}

\begin{abstract}
The objective of this work was to characterize high protein soybean near isogenic lines. The increasing of protein was followed by reducing of oil and carbohydrate. In respect to aminoacid composition, increasing of protein promoted a rising in all aminoacids, except for glycine, alanine, methionine, cysteine and tyrosine, although the ratio $\mathrm{S} / \mathrm{N}$ has been kept. The measure of polypeptides showed that the increasing of protein did not alter the quantity of 7S proteins, provided increasing of $11 \mathrm{~S}$ proteins and 11S/7S ratio. An improvement of meal quality in these lines can occur once the 11S proteins have a better nutritional quality than $7 \mathrm{~S}$ proteins.
\end{abstract}

Index terms: Glycine max, aminoacid, methionine, cysteine, 7S, 11S.

\section{Introdução}

Teores de proteína e óleo em sementes de soja determinam seu valor comercial. O farelo de soja destinado à exportação é classificado em três categorias, de acordo com seu conteúdo de proteína: HyPro (>48\%), Normal (46\%) e LowPro (<43,5\%). Para atingir o índice classificado como Normal e HyPro, a soja deve conter acima de 41,5 e $43 \%$ de proteína nas sementes, respectivamente, com base na matéria seca.

Sementes de variedades cultivadas de soja contêm cerca de $40 \%$ de proteína e $20 \%$ de óleo com base na matéria seca. As proteínas presentes em maior quantidade são as proteínas de reserva glicinina e $\beta$-conglicinina, lipoxigenases, inibidor de tripsina Kunitz, inibidores de protease de baixo peso molecular (dos quais o melhor estudado é o inibidor Bowman-Birk), lectina e urease. Dessas, glicinina e $\beta$-conglicinina são predominantes, perfazendo um total de cerca de $70 \%$ das proteínas da semente (Hill \& Breidenbach, 1974). As outras, presentes em altos teores em comparação às proteínas metabólicas, perfazem, geralmente, cerca de 2 a 5\% do total de proteína. As proteínas de reserva da soja têm coeficientes de sedimentação de, aproximadamente, 7S (composta pelas subunidades $\alpha$ ', $\alpha$ e $\beta$ ) e $11 \mathrm{~S}$ (composta pelas subunidades A1aB2, A1bB1b, A2B1a, A3B4 e A5A4B3) (Nielsen et al., 1995).

Ogawa et al. (1989) e Kitamura \& Kaizuma (1981) verificaram que linhagens com variações nos teores das proteínas 7S compensaram sua perda com o aumento na síntese e deposição das proteínas 11S (que tem maior conteúdo de metionina), mantendo assim o teor de proteína total não alterado. Conseqüentemente, isto aumentaria o conteúdo de aminoácidos sulfurados da proteína de soja (Clarke \& Wiseman, 2000). De fato, 
Kitamura (1995) demonstrou que uma linhagem mutante com baixo conteúdo de 7S apresentou aumento de cerca de 15\% nas proteínas 11S, em relação às variedades normais, sem contudo alterar o teor de proteína total e que, linhagens mutantes para baixo teor de proteínas 11S, não sofreram redução no teor de proteínas 7S.

Linhagens de alto teor de proteína parecem conter maiores teores de $\beta$-conglicinina e glicinina do que as linhagens normais, e as quantidades relativas dessas duas proteínas e de seus polipeptídeos constituintes variam entre as linhagens (Yaklich, 2001).

$\mathrm{O}$ aumento nas quantidades de proteína ocorreu à custa do teor de óleo, carboidratos totais e sacarose, além de aumento no número de aminoácidos sulfurados em linhagens com diferentes teores de proteína (Wilcox \& Shibles, 2001). No entanto, a proporção S/N (enxofre/nitrogênio) manteve-se constante entre os teores de proteína na população. Esses autores sugerem que a diminuição no teor de carboidratos totais e, principalmente, dos oligossacarídeos rafinose e estaquiose, com o aumento no teor de proteína, poderia melhorar o valor nutricional do farelo de soja. Linhagens mutantes que produzem alto teor de metionina foram cruzadas com genótipos normais e a progênie mostrou proporção de S/N 16,2\% maior que o normal. Análises de aminoácidos das sementes do progenitor recorrente e das linhagens derivadas revelaram 1,51 e 1,84 mol\%, respectivamente, para metionina e 1,32 e 1,69 mol\%, respectivamente, para cisteína. Vieira et al. (1999), ao avaliar genótipos de soja destinados à alimentação humana, mostraram que esses genótipos apresentavam excelentes balanços de aminoácidos essenciais, sendo superiores aos valores da proteína-padrão estabelecidos pela FAO/WHO.

Uma avaliação geral de um genótipo é importante no final de um programa de melhoramento, de forma que a modificação genética sofrida pela linhagem não comprometa seu valor nutricional com o melhoramento.

O objetivo deste trabalho foi caracterizar bioquimicamente duas linhagens de soja com alto teor de proteína, obtidas no programa de melhoramento da qualidade da soja para a agroindústria, do Bioagro/UFV.

\section{Material e Métodos}

Duas isolinhas de alto teor de proteína, obtidas no programa de melhoramento genético da soja para a agroindústria, do Bioagro/UFV, e a linhagem UFVTN 105 (com ausência de lipoxigenases e teor normal de proteína), todas derivadas da variedade comercial CAC-1, possuindo mesmo background genético, foram avaliadas quanto à composição bioquímica de seus grãos.

A determinação de proteínas foi efetuada pelo método de Kjeldahl para a quantificação de $\mathrm{N}$ total, descrito pela Association of Official Analytical Chemists (1975), com modificações. Na fase de digestão, após obtenção do material aparentemente digerido, adicionou-se peróxido de hidrogênio $30 \%$, levando a mistura a aquecimento por mais 30 minutos. Na fase de destilação, recolheu-se a amônia liberada em solução de ácido bórico 4\%. Obteve-se o teor de $\mathrm{N}$ pela titulação da amônia com ácido clorídrico 0,05 N. A partir do teor de $\mathrm{N}$, foi calculada a porcentagem de proteína total da amostra, empregando-se o fator 6,25. Os resultados dos teores de proteína foram expressos em porcentagem com base na matéria seca, constituindo a média de três repetições.

Determinaram-se lipídios em aparelho extrator de Soxhlet, utilizando éter de petróleo como solvente, de acordo com o procedimento descrito em normas analíticas do Instituto Adolfo Lutz (Instituto Adolfo Lutz, 1985), com refluxo por 10 horas.

As proteínas de reserva de sementes de cada genótipo foram extraídas de amostras de fragmentos dos cotilédones $(10 \mathrm{mg})$ com $900 \mu \mathrm{L}$ de tampão de extração Tris-HCl 50 mM, pH 8,0 contendo 0,2\% SDS, $10 \mathrm{mM}$ de $\beta$-mercaptoetanol e uréia $6 \mathrm{M}$. As proteínas nos extratos foram separadas em géis gradientes de poliacrilamida de 10 a 18\% (Fontes et al., 1984) contendo Tris-HCl 0,45 M, uréia 1,78 M e SDS 0,09\%, $\mathrm{pH} 8$,8. Amostras de $20 \mu \mathrm{L}$ foram aplicadas no gel e a corrida foi realizada a $80 \mathrm{~V}$ por uma hora e a $100 \mathrm{~V}$ por cinco horas. As bandas protéicas foram reveladas em solução de Coomassie Blue R-250.

A determinação do conteúdo de cinzas foi conduzida por meio da calcinação das amostras a $550^{\circ} \mathrm{C}$, conforme o método descrito em normas analíticas do Instituto Adolfo Lutz (Instituto Adolfo Lutz, 1985).

O teor de carboidratos totais foi obtido por diferença porcentual como mostrado a seguir: $\% \mathrm{CHO}=100$ (\%PTN + \%cinzas + \%óleo); em que \%CHO é o teor de carboidratos totais; \%PTN é o teor de proteína; \%cinzas é o teor de cinzas; e \%óleo é o teor de óleo.

De cada genótipo, foram analisadas duas repetições de amostras de sementes de soja moídas em moinho do tipo Wiley. A farinha obtida foi desengordurada em extrator Soxhlet. Os aminoácidos foram analisados no Centro Interdepartamental de Química de Proteínas da Faculdade de Medicina de Ribeirão Preto, Universida- 
de de São Paulo. A análise de aminoácidos foi realizada em duplicata, por hidrólise ácida, para se quantificar os aminoácidos lisina, histidina, arginina, ácido aspártico, treonina, serina, ácido glutâmico, prolina, glicina, alanina, cisteína, valina, metionina, isoleucina, leucina, tirosina e fenilalanina (Moore et al., 1958).

A composição qualitativa e quantitativa dos aminoácidos foi determinada por análise automática, pelo método de Spackman et al. (1958), utilizando-se um analisador automático (Alonzo \& Hirs, 1968).

As subunidades protéicas reveladas em gel (Figura 1) foram analisadas por densitometria em escâner "Personal Densitometer SI", da Molecular Dynamics. As subunidades das proteínas de reserva 7S e 11S de sementes de soja foram identificadas de acordo com Fontes et al. (1984). Foram feitas duas repetições de cada amostra, na qual a quantidade relativa de proteína correspondente a cada banda foi calculada em relação a uma curva-padrão estabelecida com quantidades crescentes da proteína-padrão anidrase carbônica: 2, 4, 8 e $10 \mu \mathrm{g}$.

Foram processadas análises de variância dos dados em delineamento inteiramente casualizado com três repetições por amostra, utilizando o programa estatístico genes (Cruz, 2001). Em seguida, foi efetuada comparação entre médias pelo método de Tukey a 5\% de probabilidade.

\section{Resultados e Discussão}

Os teores de proteínas obtidos foram de 40,68\% para a linhagem UFVTN 105, 47,8\% (aumento de 17,4\%) para a isolinha 1 e 46,56\% (aumento de $14,5 \%$ ) para a isolinha 2 (Tabela 1). Os teores de óleos foram de 24,03, 19,22 e 18,56\%, para a linhagem UFVTN 105, isolinha 1 e isolinha 2, respectivamente. À medida que se aumenta o teor de proteína, o teor de óleo é reduzido, comprovando a correlação negativa entre essas duas características. Vários autores relataram a correlação negativa existente entre proteína e óleo. Helms \& Orf (1998) mostraram que a seleção direta para teor de proteína produziu redução no teor de óleo. Wilcox (1998) mostrou que a seleção recorrente aumentou a média do teor de proteína nas sementes de $5,8 \mathrm{~g} \mathrm{~kg}^{-1}$ e diminuiu a média do teor de óleo de $2,3 \mathrm{~g} \mathrm{~kg}^{-1}$ por ciclo.

O teor de carboidratos foi de 30,37, 27,61 e 29,22\% para UFVTN 105, isolinha 1 e isolinha 2, respectivamente. Da mesma forma, quando se aumentou o teor de proteína, o teor de carboidratos também foi reduzido, o que evidencia associação negativa entre estas duas características. Hartwig et al. (1997) e Wilcox \& Shibles (2001) sugerem que o aumento no teor de proteína poderia reduzir o teor de açúcares solúveis presentes na fração carboidratos totais, melhorando desta forma a qualidade nutricional do farelo de soja. A Tabela 2 mostra a composição

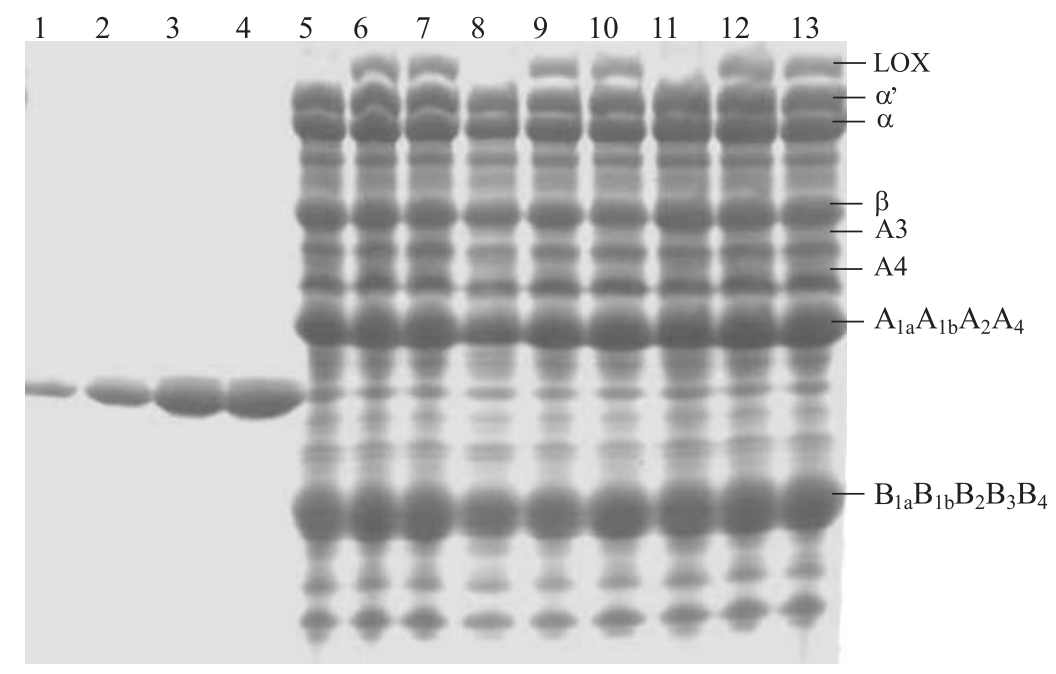

Figura 1. Análise eletroforética SDS-PAGE em gel gradiente de 10 a $18 \%$ das proteínas de soja extraídas da linhagem UFVTN 105 e das isolinhas derivadas com alto teor de proteína; canaletas 1, 2, 3 e 4 contêm 2, 4, 8 e $10 \mu \mathrm{g}$ de proteína-padrão anidrase carbônica; canaletas de 5 a 13 contêm triplicatas de proteína total extraídas da linhagem UFVTN 105 e das isolinhas 1 e 2, respectivamente. 
aminoacídica da linhagem UFVTN 105 e das isolinhas 1 e 2. Quando se considera a porcentagem de cada aminoácido na proteína da soja, o aumento do teor de proteína detectado nas linhagens melhoradas (isolinhas 1 e 2) promoveu alteração significativa na composição aminoacídica (porcentagem de cada aminoácido na proteína), exceto para glicina, alanina, metionina, cisteína e tirosina. Desta forma, considerando que metionina e cisteína são aminoácidos limitantes na proteína da soja, não houve redução do valor nutricional em relação a esses aminoácidos nas linhagens de alto teor de proteína. Takahashi et al. (2003), estudando linhagens com mutações para $7 \mathrm{~S}$ e $11 \mathrm{~S}$, mostraram que os mutantes

Tabela 1. Teores, em porcentagem, de proteína, óleo, carboidratos e cinzas das isolinhas 1 e 2 e da linhagem UFVTN 105, com base na matéria seca ${ }^{(1)}$.

\begin{tabular}{lcccc}
\hline Amostra & $\begin{array}{c}\text { Teor de } \\
\text { proteína }\end{array}$ & $\begin{array}{c}\text { Teor de } \\
\text { óleo }\end{array}$ & $\begin{array}{c}\text { Teor de } \\
\text { cinzas }\end{array}$ & $\begin{array}{c}\text { Teor de } \\
\text { carboidratos totais }\end{array}$ \\
\hline UFVTN 105 & $40,68 \mathrm{c}$ & $20,78 \mathrm{a}$ & $4,93 \mathrm{c}$ & $33,61 \mathrm{a}$ \\
Isolinha 1 & $47,78 \mathrm{a}$ & $16,81 \mathrm{~b}$ & $5,40 \mathrm{~b}$ & $30,01 \mathrm{c}$ \\
Isolinha 2 & $46,56 \mathrm{~b}$ & $16,71 \mathrm{c}$ & $5,66 \mathrm{a}$ & $31,07 \mathrm{~b}$ \\
\hline $\mathrm{QM}^{(2)}$ & $43,17^{* *}$ & $18,10^{* *}$ & $5,33^{* *}$ & $31,56^{* *}$ \\
\hline
\end{tabular}

(1)Médias seguidas de mesma letra na coluna não diferem entre si pelo teste de Tukey a 5\% de probabilidade. ${ }^{(2)}$ QM: quadrado médio. ${ }^{* *}$ Significativo a $1 \%$ de probabilidade pelo teste $\mathrm{F}$.

Tabela 2. Composição aminoacídica das farinhas desengorduradas da linhagem UFVTN 105 e das isolinhas 1 e $2^{(1)}$.

\begin{tabular}{|c|c|c|c|c|c|c|c|}
\hline \multirow[t]{2}{*}{ Aminoácido } & \multicolumn{2}{|c|}{ UFVTN 105} & \multicolumn{2}{|c|}{ Isolinha 1} & \multicolumn{2}{|c|}{ Isolinha 2} & \multirow[t]{2}{*}{ QM } \\
\hline & AAF & AAP & AAF & AAP & $\overline{\mathrm{AAF}}$ & AAP & \\
\hline Lisina & 3,20 & 6,83 & 3,65 & 7,11 & 3,30 & 6,56 & $0,15^{*}$ \\
\hline & 1,33 & 2,84 & 1,54 & 2,99 & 1,38 & 2,74 & $0,03^{*}$ \\
\hline & 3,45 & 7,37 & 4,14 & 8,08 & 3,77 & 7,48 & $0,29^{*}$ \\
\hline Ác. as & 6,16 & 13,14 & 6,29 & 12,26 & 6,44 & 12,79 & $0,39^{*}$ \\
\hline Treoni & 2,17 & 4,62 & 2,22 & 4,33 & 2,22 & 4,41 & $0,05^{*}$ \\
\hline & 2,78 & 5,94 & 2,74 & ,34 & 2,80 & ,56 & $0,19^{*}$ \\
\hline Ac. & 8,59 & 18,34 & 8,58 & 16,73 & 8,76 & 17,40 & $1,32^{*}$ \\
\hline & 2,40 & 5,11 & 2,79 & 5,44 & 2,65 & 5,25 & $0,06^{*}$ \\
\hline & 2,15 & 4,58 & 2,35 & 4,58 & 2,37 & 4,71 & $0,01^{\text {ns }}$ \\
\hline & 2,13 & 4,54 & 2,26 & 4,41 & 2,29 & 4,54 & $0,01^{\mathrm{ns}}$ \\
\hline & 0,48 & 1,03 & 0,50 & 0,97 & 0,54 & 1,06 & 0,00 \\
\hline Valin & 1,91 & 4,07 & 2,42 & 4,71 & 2,35 & 4,67 & $0,26^{*}$ \\
\hline Met & 0,62 & 1,31 & 0,67 & 1,31 & 0,66 & 1,30 & $0,00^{\text {ns }}$ \\
\hline Isole & 1,98 & 4,23 & 2,48 & 4,83 & 2,38 & 4,73 & $0,21^{*}$ \\
\hline Leuc & 3,63 & 7,75 & 4,24 & 8,27 & 4,00 & 7,95 & $0,14^{*}$ \\
\hline & 1,57 & 3,34 & 1,80 & 3,51 & 1,76 & 3,49 & $0,02^{\text {ns }}$ \\
\hline Fenilalanina & 2,32 & 4,94 & 2,63 & 5,13 & 2,70 & 5,35 & $0,08^{*}$ \\
\hline & & & & & & & \\
\hline
\end{tabular}

${ }^{(1)}$ Valores médios de duas repetições; AAF: porcentual do aminoácido na farinha desengordurada; AAP: porcentual do aminoácido por proteína;

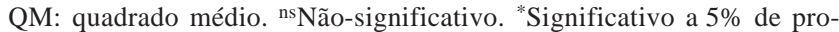
babilidade pelo teste $\mathrm{F}$. dessas proteínas compensaram sua ausência com aumento de outras proteínas e de aminoácidos livres.

A análise dos polipeptídeos constituintes das proteínas de reserva da soja no gel SDS-PAGE, em gradiente de poliacrilamida de 10 a $18 \%$ contendo uréia $6 \mathrm{M}$ (Figura 1), evidencia aumento nas quantidades das subunidades componentes da proteína glicinina nas isolinhas de alto teor de proteína. Os resultados da quantificação do gel por densitometria (Tabela 3) mostram que a quantidade da subunidade $7 \mathrm{~S}$ não foi estatisticamente diferente entre a variedade com teor normal e as linhagens de alto teor de proteína, apesar de ter havido redução na subunidade $\beta$. Por sua vez, a quantidade das proteínas 11S e a relação 11S/7S foram maiores nas isolinhas de alto teor de proteína. $\mathrm{O}$ aumento de proteínas $11 \mathrm{~S}$ foi proporcionado principalmente pelos aumentos da subunidade A4 e das subunidades básicas (Tabela 2). As proteínas $11 \mathrm{~S}$ contêm de três a quatro vezes mais metionina e cisteína por unidade de proteína do que as proteínas 7S, embora as duas possuam diferentes aspectos funcionais como capacidade de gelatinização e de emulsificação e estabilidade térmica. Desta forma, a manipulação genética da proporção 11S/7S pelo aumento ou diminuição das 7S poderia melhorar a qualidade funcional das proteínas da soja para atender necessidades específicas em sua utilização (Kitamura, 1995). Esses resultados divergem em parte dos encontrados por Yaklich (2001), que analisou variedades e linhagens de soja de alto teor de proteína, mostrando que os teores de ambas as proteínas 7S e 11S aumentam nestas linhagens e variedades. Esse autor também mostrou que os conteúdos dos polipeptídeos

Tabela 3. Quantificação das subunidades das proteínas de soja por densitometria em gel gradiente de poliacrilamida $10-18 \%$.

\begin{tabular}{|c|c|c|c|c|}
\hline Subunidades & UFVTN 105 & Isolinhal & Isolinha2 & $\mathrm{QM}^{(1)}$ \\
\hline$\alpha$ & 0,25 & 0,22 & 0,22 & $0,000811^{\mathrm{ns}}$ \\
\hline$\alpha$ & 0,40 & 0,37 & 0,37 & $0,0009^{\text {ns }}$ \\
\hline$\beta$ & 0,33 & 0,26 & 0,26 & $0,0044^{*}$ \\
\hline A3 & 0,10 & 0,11 & 0,12 & $0,0003^{\text {ns }}$ \\
\hline A4 & 0,13 & 0,19 & 0,20 & $0,0043^{*}$ \\
\hline Ácidas & 0,54 & 0,62 & 0,67 & $0,013^{\mathrm{ns}}$ \\
\hline Básicas & 0,37 & 0,66 & 0,60 & $0,07^{*}$ \\
\hline $7 \mathrm{~S}$ & 0,97 & 0,85 & 0,85 & $0,018^{\mathrm{ns}}$ \\
\hline $11 \mathrm{~S}$ & 1,13 & 1,56 & 1,58 & $0,208^{*}$ \\
\hline $11 \mathrm{~S} / 7 \mathrm{~S}$ & 1,17 & 1,85 & 1,87 & $0,528^{*}$ \\
\hline $11 \mathrm{~S}+7 \mathrm{~S}$ & 2,09 & 2,41 & 2,43 & $0,10^{\mathrm{ns}}$ \\
\hline$\%(7 \mathrm{~S}+11 \mathrm{~S})$ & 51,38 & 50,44 & 52,20 & $0,44^{\mathrm{ns}}$ \\
\hline
\end{tabular}

${ }^{(1)} \mathrm{QM}$ : quadrado médio. nsNão-Significativo. *Significativo a 5\% de probabilidade pelo teste $\mathrm{F}$. 
componentes das subunidades de cada uma das proteínas de reserva variam entre as diversas linhagens e variedades, e que algumas das linhagens de alto teor protéico apresentaram maiores acúmulos dos polipeptídios $\alpha$ ', $\alpha$ e $\beta$, componentes da proteína $\beta$-conglicinina, ao passo que todas as linhagens e variedades de alto teor protéico apresentaram maiores acúmulos dos polipeptídios de caráter ácido e básico componentes da proteína glicinina, quando comparadas com variedade-padrão.

\section{Conclusão}

1. O aumento do teor de proteína nas linhagens de soja é acompanhado por redução no teor de óleo e redução no teor de carboidratos totais.

2. Em relação à composição aminoacídica, há diferença significativa quando se observa a proporção dos aminoácidos em relação ao teor de proteína total, exceto para os aminoácidos glicina, alanina, metionina, cisteína e tirosina .

3. O aumento do teor de proteína das isolinhas é acompanhado, principalmente, pelo aumento nas quantidades das proteínas $11 \mathrm{~S}$ e da relação 11S/7S.

\section{Referências}

ALONZO, N.; HIRS, C.H.W. Automation of sample application in amino acid analyzers. Analytical Biochemistry, v. 23, p.272-288, 1968.

\section{ASSOCIATION OF OFFICIAL ANALYTICAL CHEMISTS} (Arlington, Estados Unidos). Official methods of analysis. Washington, DC, 1975. 1094p.

CLARKE, E.J.; WISEMAN, J. Developments in plant breeding for improved nutritional quality of soya beans. I. Protein and amino acid content. Journal of Agricultural Science, v.134, p.111-124, 2000.

CRUZ, C.D. Programa GENES: aplicativo computacional em genética e estatística; versão Windows. Viçosa: UFV, 2001. 648p.

FONTES, E.P.B.; MOREIRA, M.A.; DAVIES, C.S.; NIELSEN, N.C. Urea elicited changes in relative electrophoretic mobility of certain glycinin and $\beta$-conglycinin subunits. Plant Physiology, v.76, p.840-842, 1984.
HARTWIG, E.E.; KUO, T.M.; KENTY, M.M. Seed protein and its relationship to soluble sugars in soybean. Crop Science, v.37, p.770773, 1997.

HELMS, T.C.; ORF, J.H. Protein, oil and yield of soybean lines selected for increased protein. Crop Science, v.38, p.707-711, 1998.

HILL, J.E.; BREIDENBACH, R.W. Proteins of soybean seeds. II. Accumulation of the major protein components during seed development and maturation. Plant Physiology, v.53, p.747-751, 1974.

INSTITUTO ADOLFO LUTZ (São Paulo, SP). Normas analíticas do Instituto Adolfo Lutz: métodos químicos e físicos para análise de alimentos. 3.ed. São Paulo, 1985. v.1, p.533.

KITAMURA, K. Genetic improvement of nutritional and food processing quality in soybean. Japan Agricultural Research Quarterly, v.29, p.1-8, 1995.

KITAMURA, K.; KAIZUMA, N. Mutant strains with low level of subunits of 7S globulin in soybean (Glycine max Merr.) seed. Japanese Journal of Breeding, v.31, p.353-359, 1981.

MOORE, S.; SPACKMAN, D.H.; STEIN, W.H. Chromatography of amino acids on sulfonated polystyrene resins. An improved system. Analytical Chemistry, v.30, p.1185-1190, 1958.

NIELSEN, N.C.; JUNG, R.; NAM, Y.W.; BEAMAN, T.W.; OLIVEIRA, L.O.; BASSUNER, R. Synthesis and assembly of $11 \mathrm{~S}$ globulins. Journal of Plant Physiology, v.145, p.641-647, 1995.

OGAWA, T.; TAYAMA, E.; KITAMURA, K.; KAIZUMA, N. Genetic improvement of seed storage proteins using three variant alleles of 7S globulin subunits in soybean (Glycine max L.). Japanese Journal of Breeding, v.39, p.137-147, 1989.

SPACKMAN, D.H.; STEIN, W.H.; MOORE, S. Automatic recording apparatus for use in the chromatography of amino acids. Analytical Chemistry, v.30, p.1190-1206, 1958.

TAKAHASHI, M.; UEMATSU, Y.; KASHIWABA, K.; YAGASAKI, K.; HAJIKA, M.; MATSUNAGA, R.; KOMATSU, K.; ISHIMOTO, M. Accumulation of high levels of free amino acids in soybean seeds through integration of mutations conferring seed protein deficiency. Planta, v.217, p.577-586, 2003.

VIEIRA, C.R.; CABRAL, L.C.; PAULA, A.C.O. de. Proximate composition and amino acid, and fatty acid and mineral contents of six soybean cultivars for human consumption. Pesquisa Agropecuária Brasileira, v.34, p.1277-1283, 1999.

WILCOX, J.R. Increasing seed protein in soybean with eight cycles of recurrent selection. Crop Science, v.38, p.1536-1540, 1998.

WILCOX, J.R.; SHIBLES, R.M. Interrelationships among seed quality attributes in soybean. Crop Science, v.41, p.11-14, 2001.

YAKLICH, R.W. $\beta$-Conglycinin and glycinin in high protein soybean seeds. Journal of Agricultural and Food Chemistry, v.49, p.729735, 2001. 